\title{
THE LOGARITHMIC COEFFICIENT INEQUALITY FOR CLOSE-TO-CONVEX FUNCTIONS OF COMPLEX ORDER
}

\author{
MURAT ÇAĞLAR
}

Abstract. We prove that if $n \geqslant 2$ for each close-to-convex functions of complex order $b$ in $\mathscr{S}$ whose $n-t h \operatorname{logarithmic}$ coefficients $\gamma_{n}$ satisfies $\left|\gamma_{n}\right| \leqslant A n^{-1} \log n$, where $A$ is an absolute constant.

Mathematics subject classification (2010): 30C45.

Keywords and phrases: Close-to-convex functions, logarithmic coefficients, starlike functions.

\section{REFERENCES}

[1] M. K. Aouf, AND M. A. NASR, Starlike functions of complex order b, J. Natural Sci. Math. 25 (1) (1985), 1-12.

[2] H. S. Al-Amiri, S. And Fernando, On close-to-convex functions of complex order, J. Math. \& Math. Sci. Vol. 13, No. 2 (1990), 321-330.

[3] J. ANDERSON, K. BARTH, AND D. BRANNAN, Research problems in complex analysis, Bull. London Math. Soc. 9 (1977), 129-162.

[4] Q. Deng, On circularly symmetric functions, Appl. Math. Lett. 23 (2010), 1483-1488.

[5] Q. Deng, On the logarithmic coefficients of Bazilevic functions, Appl. Math. Comput. 217 (2011), 5889-5894.

[6] P. Duren,, Coefficients of univalent functions, Bull. Amer. Math. Soc. 83 (5) (1977), 891-911.

[7] P. L. Duren, Univalent Functions, Springer-Verlag, New York, 1983.

[8] P. Duren, Y. Leung,, Logarithmic coefficients of univalent functions, J. Analyse Math. 36 (1979), $36-43$.

[9] M. M. Elhosh, On the logarithmic coefficients of close-to-convex functions, J. Austral. Math. Soc. (Ser. A) 60 (1996), 1-6.

[10] D. Girela, Logarithmic coefficients of univalent functions, Annales. Acad. Sci. Fen. Math. 25 (2000), 337-350.

[11] N. A. LeBedEV,, Applications of area principle to problems on nonoverlapping domains, Trudy Mat. Inst. Stekliov, 60 (1961), 211-231 (in Russian).

[12] K. Pearce, Review of [9], Math. Reviews, info review no. 96j: 30013, 1996.

[13] Ch. Pommerenke, Univalent Functions, Vandenhoeck and Ruprecht, Göttingen, 1975.

[14] Z. YE, The logarithmic coefficients of close-to-convex functions, Bulletin of the Institute of Mathematics Academia Sinica (New Series) 3 (3) (2008), 445-452.

[15] Z. YE, The coefficients of Bazilevic functions, Complex Variables and Elliptic Equations, 58 (11) (2013), 1559-1567. 